\title{
Palliative Radiotherapy Versus Esophageal Stent Placement in the Management of Patients With Metastatic Esophageal Cancer
}

\author{
Emily J. Martin, MD¹*; Andrew R. Bruggeman, MD²,*; Vinit V. Nalawade, MS²; Reith R. Sarkar, MD²; Edmund M. Qiao, BS²; \\ Brent S. Rose, MD²; and James D. Murphy, MD, MS²
}

\begin{abstract}
Background: Patients with advanced esophageal cancer often experience pain and dysphagia, yet the optimal palliative management remains unclear. This retrospective study evaluated outcomes and adverse effects of palliative radiotherapy (RT) compared with esophageal stenting among a cohort of U.S. veterans with metastatic esophageal cancer. Patients and Methods: We identified 1,957 veterans in the United States with metastatic esophageal cancer who received palliative RT to the esophagus or esophageal stenting, and assessed the risks of severe adverse effects, including esophageal fistula formation, perforation, obstruction, hemorrhage, and esophagitis. We determined palliative efficacy by evaluating pain and dysphagia scores before and after intervention. Multivariable analyses were used to control for potential confounding factors. Results: In our cohort, 1,593 patients underwent RT and 364 underwent esophageal stenting. The cumulative incidence of any severe adverse effect at 6 months was higher among patients who received stents compared with those who received RT $(21.7 \%$ vs $12.4 \% ; P<.0010)$. In multivariable analysis, patients who received stents had an increased risk of any severe adverse effect, including fistula, perforation, and hemorrhage (all $P<.0500$ ). Multivariable analysis also showed that, compared with stenting, RT was associated with more rapid and durable pain relief $(P<.0010)$ with no difference in relief of dysphagia over time when accounting for pretreatment dysphagia scores $(P=.1029)$. Conclusions: Compared with esophageal stenting, RT was associated with a decreased risk of adverse effects, greater pain relief, and equivalent relief of moderate to severe dysphagia over time. Unmeasured patient- or tumor-related factors could have influenced the choice of intervention, thereby impacting our study outcomes. To our knowledge, this is the largest study to date analyzing the comparative risks and benefits of palliative RT and esophageal stenting among patients with metastatic esophageal cancer.
\end{abstract}

J Natl Compr Canc Netw 2020;18(5):569-574 doi: $10.6004 /$ jnccn.2019.7524

1Department of Medicine, University of California, Los Angeles, Los Angeles, California; and ${ }^{2}$ Department of Radiation Medicine and Applied Sciences, University of California, San Diego, San Diego, California.

\section{Background}

Most patients with esophageal cancer are found to have locally advanced or metastatic disease at the time of initial diagnosis. ${ }^{1-4}$ Such advanced disease is associated with significant symptom burden and corresponding decrease in quality of life. ${ }^{5}$ Dysphagia and pain, secondary to either odynophagia or local tumor extension, are the most frequently reported symptoms among patients with advanced, incurable esophageal cancer. ${ }^{4}$ Optimal treatment of these patients would ideally provide rapid and durable relief of dysphagia and pain while minimizing the risk of toxicity.

Multiple palliative treatment modalities are available for patients with metastatic esophageal cancer, though palliative radiotherapy (RT) to the esophagus and esophageal stenting are the most frequently used interventions. ${ }^{6}$ Data comparing the complication rates and palliative efficacy of these modalities are limited, however, and largely based on single-center studies with small sample sizes. ${ }^{6-8}$ The purpose of this analysis was to assess the efficacy and complications of palliative external-beam RT compared with esophageal stent placement among a large, multi-institutional cohort of veterans diagnosed with metastatic esophageal cancer.

\section{Methods}

\section{Data Source}

We conducted this study using the Veterans Affairs (VA) Informatics and Computing Infrastructure database. This database contains access patient-level electronic medical record data for all veterans within the VA healthcare system, including detailed patient, demographic, cancer, treatment, and long-term outcome information. ${ }^{9}$ The VA Institutional Review Board approved this study.

\section{See JNCCN.org for supplemental online content.}




\section{Study Subjects}

We initially identified 7,190 patients with stage IV esophageal cancer diagnosed between 2000 and 2015 from the VA Central Cancer Registry. Using ICD-9 and ICD-10 diagnosis and procedure codes, we identified 2,115 patients treated using palliative external-beam RT to the esophagus and/or esophageal stenting. The 158 patients who received both interventions were excluded because there were too few for meaningful analysis. Therefore, the final study cohort consisted of 1,957 patients. Figure 1 shows the selection process.

\section{Study Covariates}

Baseline patient, demographic, and cancer data were extracted from the VA Central Cancer Registry. Patient ZIP codes were used to estimate median household income level and population density (urban vs rural). ICD diagnosis codes in the year before initiation of cancer treatment were used to define the NCI-adapted Charlson comorbidity index, which excludes cancer-related comorbidities. ${ }^{10-13}$

\section{Study Endpoints}

Adverse effects occurring after RT or esophageal stenting were identified using ICD diagnosis codes; specifically, esophageal fistula formation, perforation, obstruction, hemorrhage, and esophagitis. We assessed efficacy of radiation or endoluminal stenting by measuring longterm pain and dysphagia scores, and extracted longitudinal pain scores for each patient (Likert scale 0-10) before and for up to 1 year after RT or stenting. All patients with at least one preintervention and one postintervention

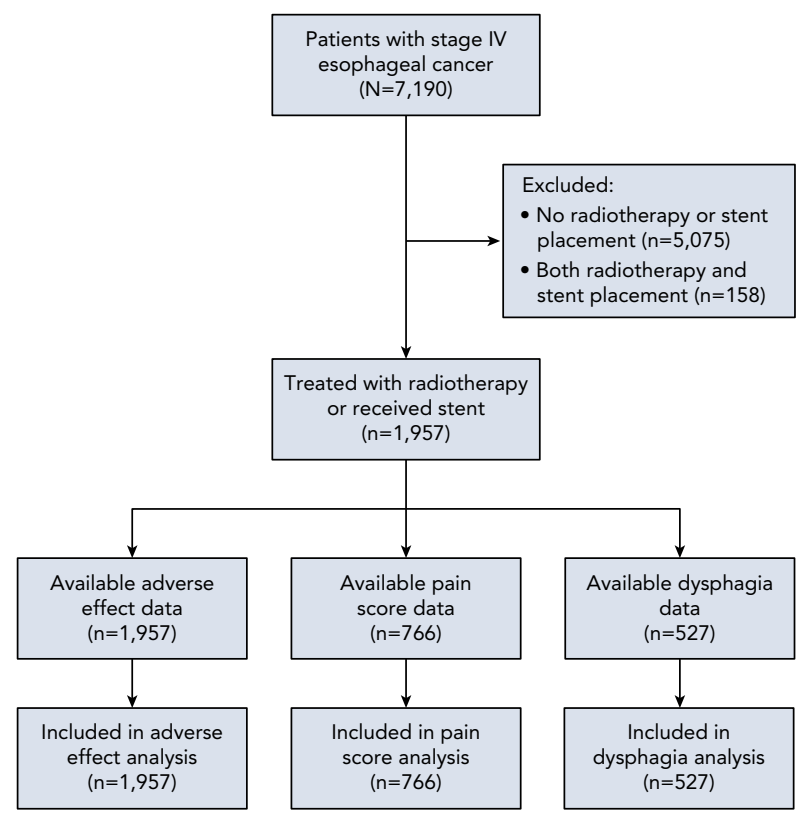

Figure 1. Patient selection. pain score were included in this subgroup analysis, with the most recent preintervention pain score serving as the patient's baseline pain level. Dysphagia scores were determined through manual review of clinical notes. We focused our review on the following keywords identifiable in clinical notes: "dysphagia," "swallow(ing)," "liquid," "solid," "stuck," "food," or "diet." Dysphagia scores were assigned using a well-established 5-point dysphagia scoring system, with 0 representing no dysphagia and 4 representing complete inability to swallow. ${ }^{14-20}$

\section{Statistical Analysis}

We assessed differences in baseline covariates between the RT and stent groups using $\chi^{2}$ and Wilcoxon rank-sum tests. We assessed the unadjusted cumulative incidence of adverse effects after RT or stenting. We measured the impact of RT or stenting on adverse effects using multivariable Fine-Gray competing risk regression, treating death as a competing risk, and censoring at last follow-up. A linear mixed effects model was used to analyze change in pain scores over time, with time serving as a continuous variable. This model was also used to analyze dysphagia scores over time. Analyses of adverse effect endpoints were conducted using the entire study cohort. Analyses of pain scores were conducted in subjects with pain scores before and up to 1 year after the intervention $(\mathrm{n}=766)$, which included a higher proportion of patients treated with RT than with stenting $(41 \%$ vs $31 \% ; P<.0010)$. Analysis of dysphagia scores was conducted in subjects with both preintervention and postintervention dysphagia scores $(n=527)$, which included a similar proportion of patients treated using RT compared with endoluminal stenting ( $28 \%$ vs $24 \% ; P=.1500$ ). To account for differences in preintervention dysphagia scores, we conducted a subgroup analysis of patients with a preintervention dysphagia score $\geq 2 \quad(n=454)$. Analyses were performed using SAS version 9.4 software (SAS Institute Inc). All tests were 2 -sided, and $P$ values $<.0500$ were considered significant.

\section{Results}

\section{Study Cohort}

Of the 1,957 patients in this study, 1,593 (81.4\%) underwent palliative RT to the esophagus and 364 (18.6\%) underwent esophageal stent placement. Table 1 contains baseline patient characteristics stratified by intervention. The 2 groups differed in terms of race, tumor histology, tumor location in the esophagus, age, and Charlson comorbidity index.

\section{Adverse Effects}

The unadjusted cumulative incidence of fistula, perforation, hemorrhage, obstruction, or esophagitis at 6 months after intervention was significantly higher for 


\section{Table 1. Baseline Patient Characteristics}

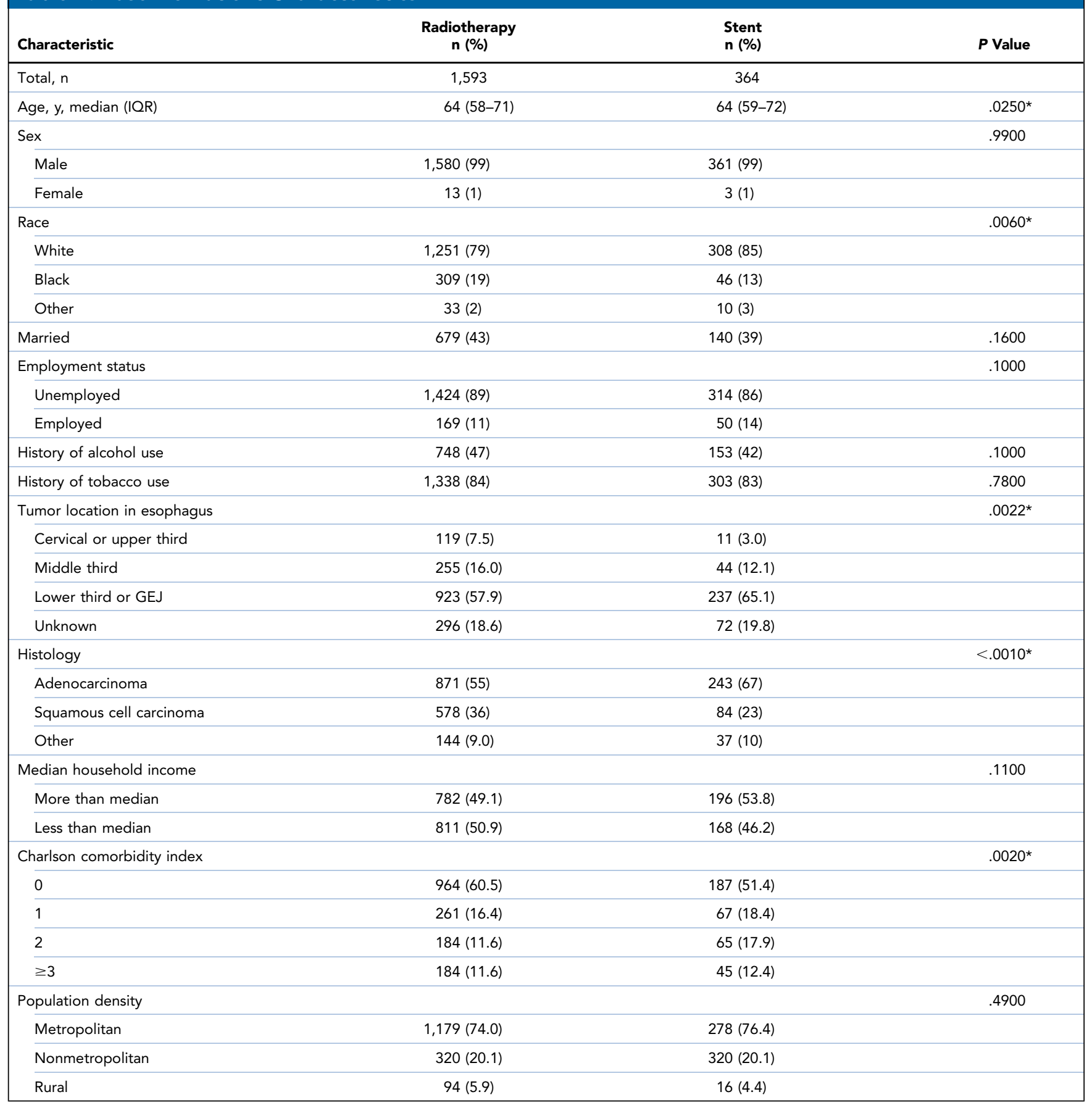

Abbreviations: GEJ, gastroesophageal junction; IQR, interquartile range.

*Meets statistical significance of $P<.0500$.

individuals who underwent stent placement than for those who underwent RT $(21.7 \%$ vs $12.4 \% ; P<.0010)$ (Figure 2A). The median time to any adverse effect was 43 days (1.41 months) for patients who received esophageal stenting and 114 days (3.75 months) for patients who received palliative RT $(P<.0010)$. When considering individual adverse effects, we found that patients receiving stents had a higher incidence of perforation and hemorrhage and a trend toward an increased incidence of fistulas (Figure 2B). These findings persisted in multivariable analysis, with patients who received stents having a $51 \%$ increased risk of any adverse effect 
A

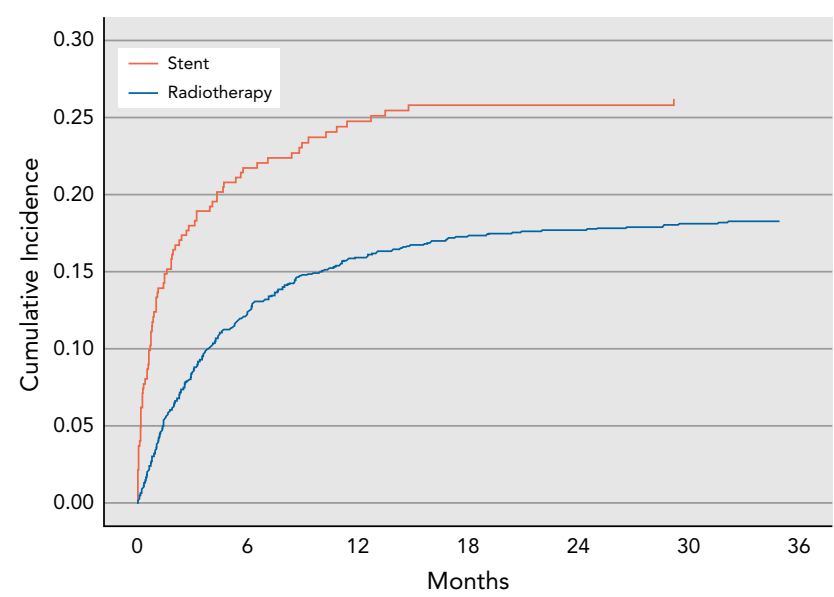

B

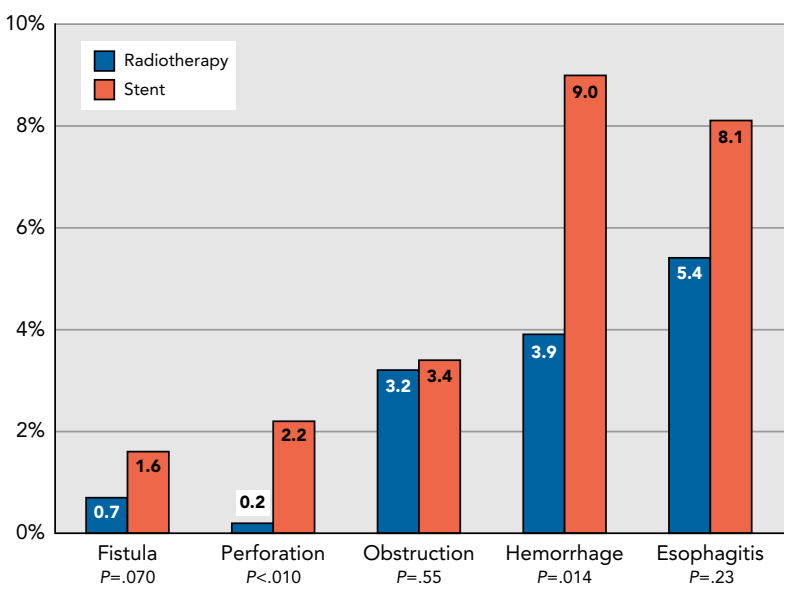

Figure 2. (A) Cumulative incidence of any adverse effect, and (B) 6-month cumulative incidence of individual adverse effects after esophageal stent placement or radiotherapy.

compared with those treated with RT (subdistribution hazard ratio [SDHR], 1.51; 95\% CI, 1.17-1.95; $P=.0014$ ). Similarly, regarding individual adverse effects in multivariable analysis, patients who underwent stent placement had an increased risk of fistula formation (SDHR, 3.56; 95\% CI, 1.49-8.48; $P=.0042$ ), perforation (SDHR, 16.89; 95\% CI, 3.95-72.25; $P<.0010$ ), and hemorrhage (SDHR, 1.51; 95\% CI, 1.01-2.26; $P=.0456$ ). In multivariable analysis, we observed no difference in the rate of obstruction (SDHR, 1.06; 95\% CI, 0.64-1.75; $P=.8155$ ) or esophagitis (SDHR, 1.21; 95\% CI, 0.81-1.81; $P=.3505$ ) between the 2 groups (supplemental eTable 1, available with this article at JNCCN.org).

\section{Palliative Efficacy}

No statistically significant differences in unadjusted preintervention pain levels were found between the stent and RT groups $(P=.3627)$. Compared with esophageal stent placement, palliative RT was associated with more rapid and persistent pain relief over time $(P<.0010)$ (Figure 3$)$. In multivariable analysis, the increased pain relief persisted for the RT group compared with the endoluminal stent group $(P<.0010)$ (supplemental eTable 2$)$. The preintervention mean dysphagia score was higher (worse) in the esophageal stent group than in the RT group $(P<.0010)$, although at 90 to 120 days, there was no difference in dysphagia $(P=.1000)$ (Figure 4). At 90 to 120 days after intervention, $75.8 \%$ of patients who received stents had a net improvement (reduction) in dysphagia compared with $58.8 \%$ of those treated with RT ( $P=.0109)$. In multivariable analysis of the 527 patients for whom we had preintervention and postintervention dysphagia scores, stenting showed a larger, more rapid improvement in dysphagia than RT over time $(P=.0190)$ (supplemental
eTable 2). In analysis of the 454 patients with a preintervention dysphagia score $\geq 2$, however, improvement in dysphagia over time was not significantly different between the groups $(P=.1029)$ (supplemental eTable 2$)$.

\section{Discussion}

Approximately $70 \%$ of patients with advanced esophageal cancer experience malignant dysphagia, which directly contributes to impaired health-related quality of life. ${ }^{21,22}$ Pain due to odynophagia or local effects of the tumor is also common and similarly associated with diminished quality of life. ${ }^{5}$ In the setting of metastatic disease, the focus of medical management is palliation of symptoms, with endoluminal stenting

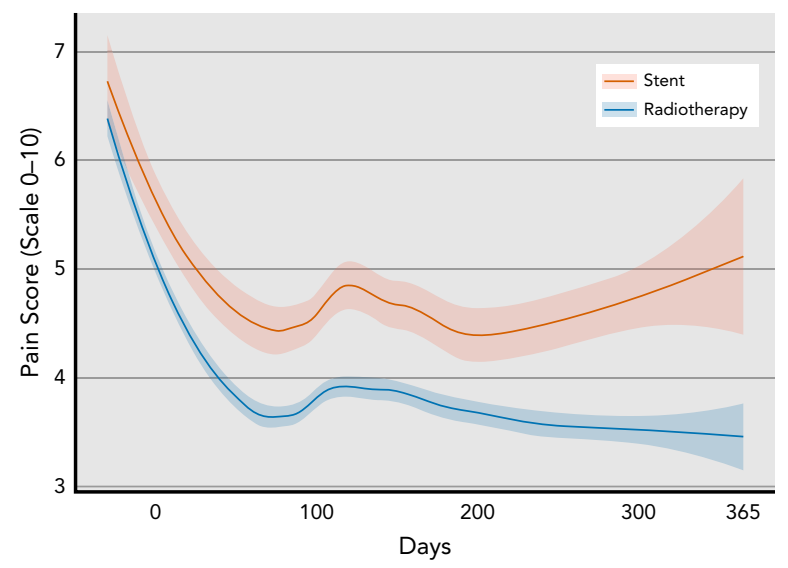

Figure 3. Pain scores over time. This plot shows a spline with $95 \%$ confidence bands (shaded regions) for patient self-reported pain scores. Time ( $x$ axis) represents days from esophageal stent placement or radiotherapy. Pain scores before time 0 reflect the last pain score within 6 months before stent placement or radiotherapy. 


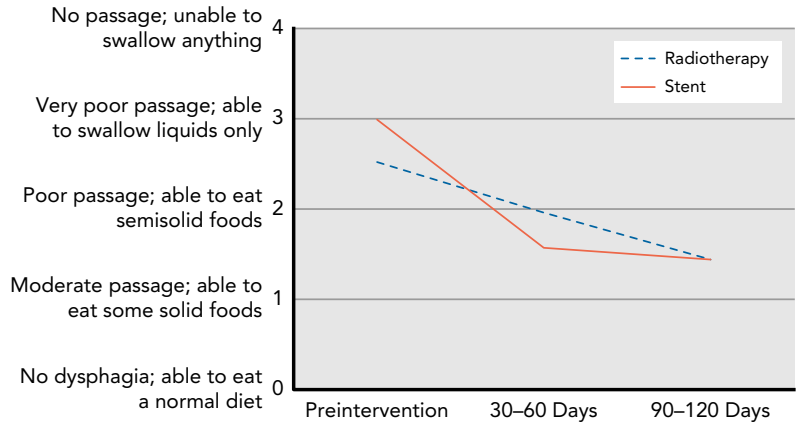

Figure 4. Average dysphagia score over time.

and external-beam RT the most commonly pursued treatment modalities. ${ }^{23-25}$ Understanding the comparative effectiveness of these 2 interventions will help define the potential benefits and risks of treatment among patients with local symptoms due to esophageal cancer.

The key finding of this study relates to the risk of adverse effects associated with the 2 interventions in this patient population. Specifically, esophageal stenting was associated with an increased risk of fistula formation, perforation, and hemorrhage compared with RT. This finding complements existing retrospective studies that have shown a $2 \%$ to $8 \%$ incidence of esophageal perforation and a 3\% incidence of fistula formation among patients treated using esophageal stenting. ${ }^{26-29}$ Regarding obstruction, the $<5 \%$ rate after stent placement in our study was much lower than the $30 \%$ to $40 \%$ rates previously described in the literature. ${ }^{26,28,29}$ In addition, our study only considered severe complications, although when considering all complications, the rate of stent-associated adverse effects in the literature ranges from $46 \%$ to $65 \%{ }^{24,30-33}$ Our study did not assess stent migration or revisions, although the literature shows that stent migration can occur in up to $20 \%$ and reintervention procedures occur in $25 \%$ to $50 \%$ of patients with stents. ${ }^{24,32-38}$ We lack large randomized trials comparing stent placement with RT, although the results of a small study involving 32 patients with advanced esophageal cancer randomized to external-beam palliative RT or stent placement have been summarized in an abstract by Turrisi et al. ${ }^{39}$ Despite its small sample size, the Turrisi et al ${ }^{39}$ study found that RT was more commonly associated with stricture and esophagitis, whereas stent placement was more commonly associated with bleeding and tumor ingrowth.

Other important observations of our study relate to the impact of these palliative modalities on symptom relief. Our study found modestly greater pain relief with palliative RT than with stenting. This difference in pain control likely reflects the antitumor effect of palliative RT, which stands in contrast to the physical effects associated with stent placement. We found that, overall, the stent group had more severe preintervention dysphagia than the RT group, a difference also noted in the existing literature. ${ }^{23}$ Because the onset of relief of dysphagia after RT is typically measured in weeks, stenting is often favored for patients with nearly complete esophageal obstruction or a very limited life expectancy, when rapid onset of relief is a priority. ${ }^{23,24}$ Importantly, however, the literature also shows a durable response with RT in up to $90 \%$ of patients. ${ }^{27,36,40-42}$ Our study complements these findings with a similar long-term reduction in dysphagia associated with RT, although it also shows persistent relief of dysphagia with stenting at 90 to 120 days. Notably, among patients with a preintervention dysphagia score $\geq 2$, improvement of this symptom over time was not significantly different between the 2 treatment groups.

Our study has limitations. As with most nonrandomized observational research, the potential of unmeasured patient-, disease-, institution-, and physician-associated confounding factors that may contribute to the observed outcomes must be considered. Because of the complexity of treatment in this patient cohort, we did not include other treatment-related factors, such as chemotherapy or pain medications received before, concurrent with, or after the 2 interventions we assessed. Given the typical multimodal approach to symptom control in patients with advanced esophageal cancer, one must consider that these ancillary treatments could influence dysphagia or pain. Additionally, in research involving electronic health records, the possibility exists of misclassification (or underreporting) of study endpoints, including pain, dysphagia, or adverse effects. Finally, although we can assess correlation between treatment modality (stent placement or RT) and our study endpoints, we lack the ability to establish causality. Pain, dysphagia, or adverse effects in this study could all arise (or improve) due to factors unrelated to esophageal stenting or RT. Despite these limitations, our study provides practical evidence for practitioners and patients to consider when choosing between palliative RT and esophageal stenting.

\section{Conclusions}

Our results support prior evidence that in patients with metastatic esophageal cancer, palliative RT is associated with significantly lower risk of toxicity, improved pain control, and equivalent relief of moderate to severe dysphagia compared with esophageal stenting. Prospective trials are needed to fully understand the comparative effectiveness of palliative RT and stent placement in metastatic esophageal cancer.

Submitted July 14, 2019; accepted for publication December 11, 2019.

Author contributions: Study concept: Martin, Bruggeman, Murphy. Data curation: All authors. Formal analysis: Nalawade, Sarkar, Murphy. Investigation: Martin, Bruggeman, Qiao, Murphy. Methodology: Martin, Bruggeman, Nalawade, Murphy. Writing - original draft: Martin, Bruggeman, Murphy. Writing - reviewing and editing: All authors. 
Disclosures: The authors have disclosed that they have not received any financial consideration from any person or organization to support the preparation, analysis, results, or discussion of this article.
Correspondence: Emily J. Martin, MD, Department of Medicine, University of California, Los Angeles, 757 Westwood Plaza, Suite 7501, Los Angeles, CA 90095. Email: ejmartin@mednet.ucla.edu

\section{References}

1. Enzinger PC, Mayer RJ. Esophageal cancer. N Engl J Med 2003;349: 2241-2252.

2. Besharat $\mathrm{S}$, Jabbari $\mathrm{A}$, Semnani $\mathrm{S}$, et al. Inoperable esophageal cancer and outcome of palliative care. World J Gastroenterol 2008;14:3725-3728.

3. Ramakrishnaiah VPN, Malage S, Sreenath GS, et al. Palliation of dysphagia in carcinoma esophagus. Clin Med Insights Gastroenterol 2016;9:11-23.

4. Javle M, Ailawadhi S, Yang GY, et al. Palliation of malignant dysphagia in esophageal cancer: a literature-based review. J Support Oncol 2006;4: 365-373, 379

5. Darling GE. Quality of life in patients with esophageal cancer. Thorac Surg Clin 2013;23:569-575.

6. Eldeeb $\mathrm{H}, \mathrm{El}-\mathrm{Hadaad} \mathrm{HA}$. Radiotherapy versus stenting in treating malignant dysphagia. J Gastrointest Oncol 2012;3:322-325.

7. Bergquist $\mathrm{H}$, Wenger $\mathrm{U}$, Johnsson $\mathrm{E}$, et al. Stent insertion or endoluminal brachytherapy as palliation of patients with advanced cancer of the esophagus and gastroesophageal junction: results of a randomized, controlled clinical trial. Dis Esophagus 2005;18:131-139.

8. Cwikiel M, Cwikiel W, Albertsson M. Palliation of dysphagia in patients with malignant esophageal strictures: comparison of results of radiotherapy, chemotherapy and esophageal stent treatment. Acta Oncol 1996:35:75-79.

9. Commission on Cancer. FORDS: Facility Oncology Registry Data Standards. Revised for 2016. Accessed May 4, 2019. Available at: https://www.facs.org/ $\sim /$ media/files/quality\%20programs/cancer/ncdb/fords\%202016.ashx

10. Charlson ME, Pompei $\mathrm{P}$, Ales $\mathrm{KL}$, et al. A new method of classifying prognostic comorbidity in longitudinal studies: development and validation. J Chronic Dis 1987;40:373-383.

11. Deyo RA, Cherkin DC, Ciol MA. Adapting a clinical comorbidity index for use with ICD-9-CM administrative databases. J Clin Epidemiol 1992;45: 613-619.

12. Romano PS, Roos LL, Jollis JG. Adapting a clinical comorbidity index for use with ICD-9-CM administrative data: differing perspectives. J Clin Epidemiol 1993;46:1075-1079, discussion 1081-1090.

13. Klabunde CN, Potosky AL, Legler JM, et al. Development of a comorbidity index using physician claims data. J Clin Epidemiol 2000;53:1258-1267.

14. Ogilvie AL, Dronfield MW, Ferguson R, et al. Palliative intubation of oesophagogastric neoplasms at fibreoptic endoscopy. Gut 1982;23: 1060-1067.

15. Penniment MG, De leso PB, Harvey JA, et al. Palliative chemoradiotherapy versus radiotherapy alone for dysphagia in advanced oesophageal cancer: a multicentre randomised controlled trial (TROG 03.01). Lancet Gastroenterol Hepatol 2018;3:114-124.

16. Homs MY, Essink-Bot ML, Borsboom GJJ, et al. Quality of life after palliative treatment for oesophageal carcinoma - a prospective comparison between stent placement and single dose brachytherapy. Eur J Cancer 2004;40:1862-1871

17. Battersby NJ, Bonney GK, Subar D, et al. Outcomes following oesophageal stent insertion for palliation of malignant strictures: a large single centre series. J Surg Oncol 2012;105:60-65.

18. Shenfine J, McNamee P, Steen N, et al. A randomized controlled clinical trial of palliative therapies for patients with inoperable esophageal cancer. Am J Gastroenterol 2009;104:1674-1685

19. O'Donnell CA, Fullarton GM, Watt E, et al. Randomized clinical trial comparing self-expanding metallic stents with plastic endoprostheses in the palliation of oesophageal cancer. Br J Surg 2002;89:985-992.

20. Mellow MH, Pinkas H. Endoscopic laser therapy for malignancies affecting the esophagus and gastroesophageal junction: analysis of technical and functional efficacy. Arch Intern Med 1985;145:1443-1446.

21. Ayres A, Jotz GP, Rieder CR de M, et al. The impact of dysphagia therapy on quality of life in patients with Parkinson's disease as measured by the Swallowing Quality of Life Questionnaire (SWALQOL). Int Arch Otorhinolaryngol 2016;20:202-206.
22. Diamantis G, Scarpa M, Bocus $P$, et al. Quality of life in patients with esophageal stenting for the palliation of malignant dysphagia. World $J$ Gastroenterol 2011;17:144-150.

23. Hanna WC, Sudarshan M, Roberge D, et al. What is the optimal management of dysphagia in metastatic esophageal cancer? Curr Oncol 2012;19:e60-66.

24. Anderloni A, Lollo G, Repici A. Palliation of malignant dysphagia and esophageal fistulas. In: Chandrasekhara V, Elmunzer BJ, Khashab MA, et al, eds. Clinical Gastrointestinal Endoscopy, 3rd ed. Philadelphia, PA: Elsevier; 2019:316-321.

25. Siersema PD, Dees J, van Blankenstein M. Palliation of malignant dysphagia from oesophageal cancer. Scand J Gastroenterol Suppl 1998;225: 75-84.

26. Katsoulis IE, Karoon A, Mylvaganam S, et al. Endoscopic palliation of malignant dysphagia: a challenging task in inoperable oesophageal cancer. World J Surg Oncol 2006;4:38.

27. Murray LJ, Din OS, Kumar VS, et al. Palliative radiotherapy in patients with esophageal carcinoma: a retrospective review. Pract Radiat Oncol 2012;2: 257-264.

28. Baron TH. Minimizing endoscopic complications: endoluminal stents. Gastrointest Endosc Clin N Am 2007;17:83-104, vii.

29. Kim JY, Kim SG, Lim JH, et al. Clinical outcomes of esophageal stents in patients with malignant esophageal obstruction according to palliative additional treatment. J Dig Dis 2015;16:575-584.

30. Wenger $U$, Luo J, Lundell $L$, et al. A nationwide study of the use of selfexpanding stents in patients with esophageal cancer in Sweden. Endoscopy 2005;37:329-334

31. Elphick DA, Smith BA, Bagshaw J, et al. Self-expanding metal stents in the palliation of malignant dysphagia: outcome analysis in 100 consecutive patients. Dis Esophagus 2005;18:93-95.

32. Reijm AN, Didden P, Schelling SJC, et al. Self-expandable metal stent placement for malignant esophageal strictures-changes in clinical outcomes over time. Endoscopy 2019;51:18-29.

33. Martinez JC, Puc MM, Quiros RM. Esophageal stenting in the setting of malignancy. ISRN Gastroenterol 2011;2011:719575.

34. Reijm AN, Didden P, Bruno MJ, et al. Early pain detection and management after esophageal metal stent placement in incurable cancer patients: a prospective observational cohort study. Endosc Int Open 2016 04:E890-894.

35. Vermeulen BD, Siersema PD. Esophageal stenting in clinical practice: an overview. Curr Treat Options Gastroenterol 2018;16:260-273.

36. Bown SG. Palliation of malignant dysphagia: surgery, radiotherapy, laser, intubation alone or in combination? Gut 1991;32:841-844.

37. Pavlidis TE, Pavlidis ET. Role of stenting in the palliation of gastroesophageal junction cancer: a brief review. World J Gastrointest Surg 2014;6:38-41.

38. Gray RT, O'Donnell ME, Scott RD, et al. Self-expanding metal stent insertion for inoperable esophageal carcinoma in Belfast: an audit of outcomes and literature review. Dis Esophagus 2011;24:569-574.

39. Turrisi AT, Hawes RH, Palesch Y, et al. The SORTIE trial: palliation with stent (S) or radiation therapy (RT) 20 Gy in 5 fractions intervention for esophageal cancer dysphagia: a multicenter trial for T-4, $\mathrm{M}+/-$ squamous or adenocarcinoma of the esophagus. A randomized trial relief from dysphagia and quality of life (QOL) analysis. Int J Radiat Oncol Biol Phys 2002;54(Suppl): 132.

40. Welsch J, Kup PG, Nieder C, et al. Survival and symptom relief after palliative radiotherapy for esophageal cancer. J Cancer 2016;7:125-130.

41. Kumar S, Dimri K, Khurana R, et al. A randomised trial of radiotherapy compared with cisplatin chemo-radiotherapy in patients with unresectable squamous cell cancer of the esophagus. Radiother Oncol 2007;83:139-147.

42. Prasad NRV, Karthigeyan M, Vikram K, et al. Palliative radiotherapy in esophageal cancer. Indian J Surg 2015;77:34-38.

See JNCCN.org for supplemental online content. 
Supplemental online content for:

\section{Palliative Radiotherapy Versus Esophageal Stent Placement in the Management of Patients With Metastatic Esophageal Cancer}

Emily J. Martin, MD; Andrew R. Bruggeman, MD; Vinit V. Nalawade, MS; Reith R. Sarkar, MD; Edmund M. Qiao, BS; Brent S. Rose, MD; and James D. Murphy, MD, MS

J Natl Compr Canc Netw 2020;18(5):569-574

eTable 1: Multivariable Fine-Gray Model Results

eTable 2: Multivariable Linear Mixed-Effects Model Results 


\section{eTable 1. Multivariable Fine-Gray Model Results}

Parameter

$P$ Value

SDHR

Fistula

Intervention (stent vs radiation)

Race (nonwhite vs white)

Age at diagnosis

Alcohol history

Tobacco history

Histology (adenocarcinoma vs SCC)

Histology (other vs SCC)

Perforation

\begin{tabular}{lcc}
\hline Intervention (stent vs radiation) & $<.0010$ & $16.89(3.95-72.25)$ \\
\hline Race (nonwhite vs white) & .8695 & $1.14(0.24-5.32)$ \\
\hline Age at diagnosis & .1410 & $0.96(0.92-1.01)$ \\
\hline Alcohol history & .9123 & $0.93(0.24-3.61)$ \\
\hline Tobacco history & .7418 & $1.33(0.24-7.33)$ \\
\hline Histology (adenocarcinoma vs SCC) & .2896 & $0.46(0.11-1.93)$ \\
\hline Histology (other vs SCC) & $<.0010$ & $0.00(0.00-0.00)$
\end{tabular}

Hemorrhage

Intervention (stent vs radiation)

Race (nonwhite vs white) .0456 $1.51(1.01-2.26)$

Age at diagnosis

$.3643 \quad 0.79(0.48-1.31)$

Alcohol history

.0023

0.97 (0.96-0.99)

Tobacco history

$.9919 \quad 1.00(0.69-1.47)$

Histology (adenocarcinoma vs SCC)

.7618

$1.08(0.66-1.76)$

$.0405 \quad 1.57(1.02-2.42)$

Histology (other vs SCC)

.3995

$1.34(0.68-2.64)$

Obstruction

Intervention (stent vs radiation)

Race (nonwhite vs white)

Age at diagnosis

Alcohol history

Tobacco history .8155

$1.06(0.64-1.75)$

Histology (adenoca

Histology (other vs SCC)

Esophagitis

Intervention (stent vs radiation)

Race (nonwhite vs white)

Age at diagnosis

Alcohol history

Tobacco history

Histology (adenocarcinoma vs SCC)

Histology (other vs SCC) .5800

$.5800 \quad 0.86(0.50-1.47)$

$.6066 \quad 1.00(0.98-1.01)$

$.3702 \quad 0.83(0.55-1.25)$

.3889 $1.26(0.75-2.13)$

$.0042 \quad 2.00(1.25-3.22)$

$.9764 \quad 0.99(0.40-2.44)$

$.3505 \quad 1.21(0.81-1.81)$

$.9813 \quad 1.01(0.66-1.54)$

$0019 \quad 0.97(0.96-0.99)$

$.9869 \quad 1.00(0.74-1.37)$

$.8080 \quad 1.06(0.69-1.62)$

$.3205 \quad 1.22(0.83-1.79)$

$.9629 \quad 0.99(0.53-1.84)$

(continued)

\section{eTable 1. Multivariable Fine-Gray Model Results} (cont.)

\begin{tabular}{|lcc|}
\hline Parameter & P Value & SDHR \\
\hline Any toxicity & & \\
\hline Intervention (stent vs radiation) & .0014 & $1.51(1.17-1.95)$ \\
\hline Race (nonwhite vs white) & .4902 & $0.91(0.69-1.20)$ \\
\hline Age at diagnosis & $<.0010$ & $0.98(0.97-0.99)$ \\
\hline Alcohol history & .4262 & $0.92(0.74-1.13)$ \\
\hline Tobacco history & .7101 & $1.06(0.79-1.41)$ \\
\hline Histology (adenocarcinoma vs SCC) & .0731 & $1.25(0.98-1.61)$ \\
\hline Histology (other vs SCC) & .8154 & $0.95(0.63-1.43)$ \\
\hline
\end{tabular}

Abbreviations: SCC, squamous cell carcinoma; SDHR, subdistribution hazard ratio. 


\begin{tabular}{|c|c|c|}
\hline Parameter/Effect & Estimate & $P$ Value \\
\hline \multicolumn{3}{|l|}{ Dysphagia } \\
\hline Intercept & 2.7668 & $<.0010$ \\
\hline Time, $d$ & -0.0074 & $<.0010$ \\
\hline Charlson comorbidity index score ( 0 vs $\geq 3$ ) & -0.0523 & .6917 \\
\hline Charlson comorbidity index score ( 1 vs $\geq 3$ ) & 0.1550 & .3245 \\
\hline Charlson comorbidity index score ( 2 vs $\geq 3$ ) & -0.1324 & .4229 \\
\hline $\begin{array}{l}\text { Income (more than median vs less than } \\
\text { median) }\end{array}$ & -0.0441 & .5934 \\
\hline Population density (metropolitan vs rural) & 0.1699 & .3004 \\
\hline Population density (nonmetropolitan vs rural) & 0.0530 & .7733 \\
\hline Intervention (radiation vs stent) & -0.2768 & .0231 \\
\hline $\begin{array}{l}\text { Tumor location in esophagus (unknown vs } \\
\text { middle third) }\end{array}$ & -0.2159 & .1352 \\
\hline $\begin{array}{l}\text { Tumor location in esophagus (cervical or } \\
\text { upper third vs middle third) }\end{array}$ & -0.0307 & .8754 \\
\hline $\begin{array}{l}\text { Tumor location in esophagus (lower third or } \\
\text { GEJ vs middle third) }\end{array}$ & -0.3938 & .0014 \\
\hline $\begin{array}{l}\text { Interaction between time and intervention } \\
\text { (radiation vs stent) }\end{array}$ & 0.0031 & .0190 \\
\hline \multicolumn{3}{|l|}{ Baseline dysphagia score $\geq 2$} \\
\hline Intercept & 2.9486 & $<.0010$ \\
\hline Time, $d$ & -0.0077 & $<.0010$ \\
\hline Charlson comorbidity index score ( 0 vs $\geq 3$ ) & -0.2100 & .1048 \\
\hline Charlson comorbidity index score ( 1 vs $\geq 3$ ) & -0.0003 & .9983 \\
\hline Charlson comorbidity index score ( 2 vs $\geq 3$ ) & -0.2692 & .0929 \\
\hline Income (above median vs below median) & -0.0255 & .7459 \\
\hline Population density (metropolitan vs rural) & 0.0408 & .7980 \\
\hline Population density (nonmetropolitan vs rural) & -0.0151 & .9332 \\
\hline Intervention (radiation vs stent) & -0.0456 & .6887 \\
\hline $\begin{array}{l}\text { Tumor location in esophagus (unknown vs } \\
\text { middle third) }\end{array}$ & -0.0950 & .4860 \\
\hline $\begin{array}{l}\text { Tumor location in esophagus (cervical or } \\
\text { upper third vs middle third) }\end{array}$ & -0.0148 & .9353 \\
\hline $\begin{array}{l}\text { Tumor location in esophagus (lower third or } \\
\text { GEJ vs middle third) }\end{array}$ & -0.2923 & .0104 \\
\hline $\begin{array}{l}\text { Interaction between time and intervention } \\
\text { (radiation vs stent) }\end{array}$ & 0.0021 & .1029 \\
\hline
\end{tabular}

(continued)

\begin{tabular}{|c|c|c|}
\hline Parameter/Effect & Estimate & $P$ Value \\
\hline \multicolumn{3}{|l|}{ Pain } \\
\hline Intercept & 2.6758 & $<.0010$ \\
\hline Time, $d$ & 0.0084 & $<.0010$ \\
\hline Charlson comorbidity index score ( 0 vs $\geq 3$ ) & -0.1790 & .6230 \\
\hline Charlson comorbidity index score ( 1 vs $\geq 3$ ) & 0.2284 & .5822 \\
\hline Charlson comorbidity index score ( 2 vs $\geq 3$ ) & -0.6761 & .1161 \\
\hline Income (above median vs below median) & -0.3664 & .0915 \\
\hline Population density (metropolitan vs rural) & 0.1475 & .7343 \\
\hline Population density (nonmetropolitan vs rural) & 0.2524 & .6024 \\
\hline Intervention (radiation vs stent) & -0.3321 & .3627 \\
\hline $\begin{array}{l}\text { Tumor location in esophagus (unknown vs } \\
\text { middle third) }\end{array}$ & -0.4439 & .2512 \\
\hline $\begin{array}{l}\text { Tumor location in esophagus (cervical or } \\
\text { upper third vs middle third) }\end{array}$ & -0.0986 & .8461 \\
\hline $\begin{array}{l}\text { Tumor location in esophagus (lower third or } \\
\text { GEJ vs middle third) }\end{array}$ & 0.0556 & .8627 \\
\hline $\begin{array}{l}\text { Interaction between time and intervention } \\
\text { (radiation vs stent) }\end{array}$ & -0.0040 & $<.0010$ \\
\hline
\end{tabular}

Abbreviation: GEJ, gastroesophageal junction. 